\title{
A Non-Blinded, Case Controlled Pilot Study to Evaluate a Novel Mask Ventilation Technique in Patients with Established Risk Factors for Difficult Mask Ventilation
}

\author{
Dennis Grech ${ }^{*}$, David Kam¹, Gregory Bryan' ${ }^{2}$, Harry Israel ${ }^{1}$, Alex Bekker1 \\ ${ }^{1}$ Department of Anesthesia and Perioperative Care, Rutgers New Jersey Medical School, Newark, NJ, USA \\ ${ }^{2}$ Department of Anesthesiology, Albert Einstein College of Medicine, Montefiore Medical Center, Bronx, NY, USA \\ Email: * grechde@njms.rutgers.edu
}

How to cite this paper: Grech, D., Kam, D., Bryan, G., Israel, H. and Bekker, A. (2016) A Non-Blinded, Case Controlled Pilot Study to Evaluate a Novel Mask Ventilation Technique in Patients with Established Risk Factors for Difficult Mask Ventilation. Open Journal of Anesthesiology, 6, 165-174. http://dx.doi.org/10.4236/ojanes.2016.610025

Received: April 16, 2016

Accepted: September 27, 2016

Published: September 30, 2016

Copyright $\odot 2016$ by authors and Scientific Research Publishing Inc. This work is licensed under the Creative Commons Attribution International License (CC BY 4.0).

http://creativecommons.org/licenses/by/4.0/

(c) () Open Access

\begin{abstract}
Traditionally, there are two main methods of mask placement during face mask ventilation: one handed (CE) grip and two handed grip (THT). One handed grip is limited by air leaks between mask and patients face on the side opposite to stabilizing hand. Two handed grips provide protection against air leak but require second provider to deliver tidal volumes when using a self inflating bag or anesthesia circuit on manual ventilation. This study introduces modified CE grip which creates a firm seal at patient's face on both sides of mask, enabling adequate tidal volume delivery with provider's second hand. Using left hand, provider places the fifth digit along inferior border of body of left mandible. The fourth digit is placed along inferior border of body right mandible. Standing 6 inches to the left and immediately behind a supine patient on an OR table, provider rotates clockwise 45 degrees at hip, keeping elbow against their body, and lifts patient's chin to 45 degrees. Rotational force at hip augments hand strength while tilting chin. The thumb applies pressure along left border of facemask, and the second and third digits apply pressure to right border of facemask. Methods: Patients with known predictors of difficult mask ventilation (Edentulous, bearded, Obstructive sleep apnea (OSA), mallampati 3 or 4) were in experimental group. Normal patients assigned as Controls. After induction of general anesthesia, provider ventilated patient using adult sized facemask. The anesthesia ventilator delivered standardized tidal volumes. TV, airway pressures, $\mathrm{HR}$ and $\mathrm{O} 2$ saturation were recorded after each breath. Results: All groups, except OSA, showed improvement, in tidal volumes with the novel technique compared to the traditional CE grip. Conclusion: The novel submandibular technique, an important skill, increases tidal volumes during mask ventilation for certain high risk patients.
\end{abstract}




\section{Keywords}

Mask Ventilation, CE Grip, Tidal Volume, Airway Skills

\section{Introduction}

Mask ventilation, a vital technique that should be mastered by virtually all medical personnel, has the capacity to save lives in acute care settings, in remote field situations, and in procedures performed with sedation [1]. Pre-operative assessment of the risk of a "difficult airway" is required by the Joint Commission and Centers for Medicare and Medicaid Services, and is recommended by the American Society of Anesthesiologists [2] [3]. Advances in mask ventilation technique that allow it to be performed with greater success for a wider range of patients may therefore have a profound impact on morbidity and mortality.

The study of predictors of difficult mask ventilation (DMV) began with Langeron et al., who defined DMV as "the inability of an unassisted anesthesiologist to maintain the measured oxygen saturation as measured by pulse oximetry $>92 \%$ or to prevent or reverse signs of inadequate ventilation during positive-pressure mask ventilation under general anesthesia". They found that the incidence of DMV was approximately 5\% [4]. DMV has since then been attributed to a number of factors, including advanced age, male sex, obesity, and Mallampati classification; presence of a beard, a thick neck, or neck masses; and limited neck extension, thyromental distance, and jaw protrusion [5]-[7].

Analyses of these factors found that a body mass index of $30 \mathrm{~kg} / \mathrm{m}^{2}$ or greater, the presence of a beard, Mallampati classification III or IV, age of 57 or older, severely limited jaw protrusion, and snoring are independent risk factors for a grade $3 \mathrm{DMV}$ airway (inadequate, unstable, or requiring two providers). Independent risk factors for grade 4 "impossible mask ventilation" include snoring and thyromental distance of less than $6 \mathrm{~cm}[8]$.

In cases of DMV, several variants of mask ventilation technique have differing levels of success. Techniques that have been developed include the one-handed C-E technique (Figure 1), the two-handed C-E technique and the two-handed V-E technique (Figure 2) [9].

The one-handed C-E technique requires the provider to use his or her thumb and forefinger to form a " $\mathrm{C}$ " shape over the mask, and generating a seal through application of downward pressure. The other three fingers are positioned under the mandible to produce head tilt [10]. The most common reason for failure to ventilate with the onehanded C-E technique is air leak on the side opposite to the stabilizing hand [11].

As a number of predictors of DMV may cause the facemask seal to be inadequate, an alternative technique that minimizes air leak may be of utility in patients with known risk factors for DMV. This study proposes a novel sub-mandibular one-handed grip that allows a sole provider to apply pressure on the left and right borders of the facemask during mask ventilation (Figure 3 and Figure 4). 


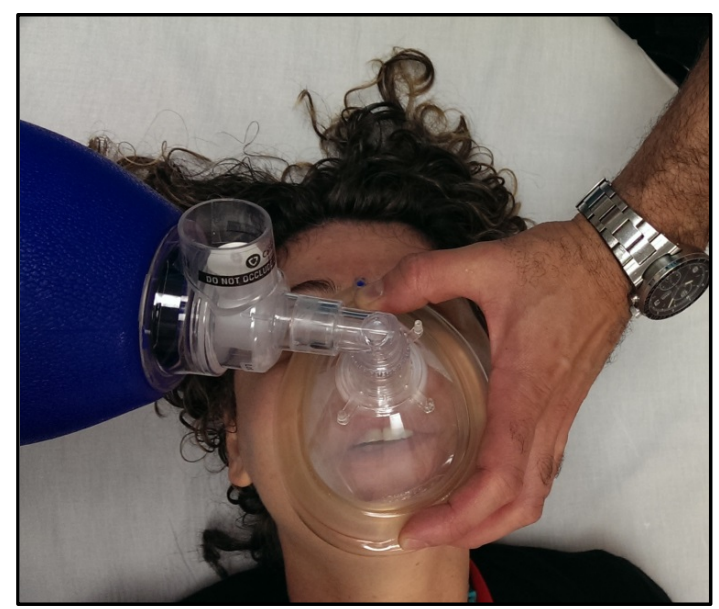

Figure 1. Traditional CE Grip showing right side of mask has potential for air leak due to poor seal between mask surface and the patient's face.

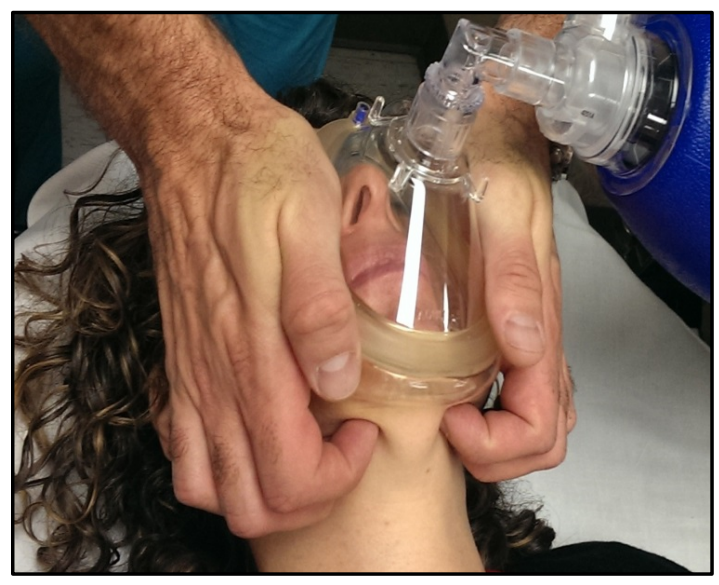

Figure 2. Two handed grip. Left and Right hands secure facemask to mandible eliminating air leak. A second provider is needed to deliver ventilations by compressing the self inflating bag.

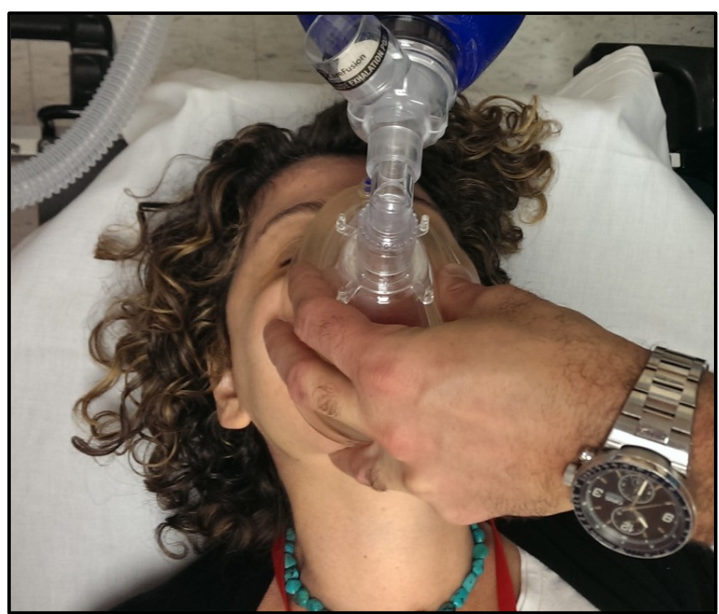

Figure 3. Novel Submandibular One Handed Grip demonstrating placement of first finger (Thumb) on the left side of the mask and fingers 2, 3 on the right side of the mask preventing air leak along right side of mask. 


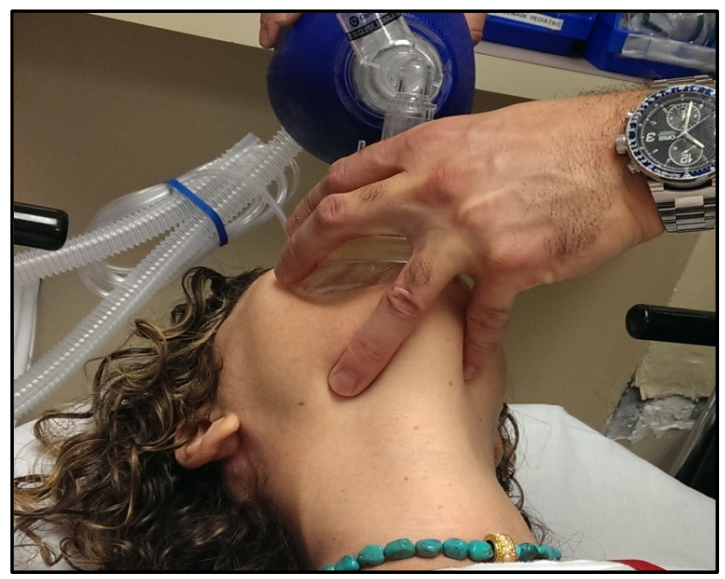

Figure 4. Novel Submandibular One Handed Grip demonstrating placement of the 5th digit along inferior border of left body of mandible. The 4th digit is placed along the inferior border of the right body of mandible. This finger placement anchors mask and provides for 45 degree chin tilt.

\section{Methods}

\subsection{Patient Selection}

The study dates were from June, 2012 to December, 2014. Following IRB approval, 28 patients from ages 18-85 who were to receive general anesthesia were enlisted for the study. Study subjects were included based on attributes that placed them in the following patient groups: edentulous, bearded, obstructive sleep apnea, Mallampati Class III or IV, previous neck radiation, and obesity with body mass index $\geq 30$ and $\leq 45$. The control group was comprised of subjects assigned Mallampati Class I or II who had no predictors of DMV. Patients with history of difficult airway, full stomach, ASA class 4 or higher, body mass index $>45$, loose teeth, or cervical instability were excluded from the study.

\subsection{Provider Selection}

All airway providers were attending anesthesiologists or certified nurse anesthetists with at least one year of work experience. Data collected about the professional participants included gender and age range.

\subsection{Novel Submandibular Technique}

To perform the NST, the anesthesia provider (AP) stood perpendicular to the long axis of the patient's body, aligning the AP's umbilicus to the patient's mentum. Next, the AP placed their fifth digit along the body of the left mandible. The fourth digit was placed along the body of the right mandible. The AP rotated clockwise at the hip while keeping their elbow against their body to lift the patient's chin to 45 degrees. This rotational force adds strength to the chin lift maneuver. The AP avoided pressing the soft tissue in the submental triangle. The first digit was used to apply pressure to the left border of the facemask, while the second and third digits are used to apply pressure to the right border of the facemask. In this way, the provider applied pressure to both the left and 
right borders of the facemask, eliminating the air-leak commonly observed when utilizing the C-E one-handed technique (Figure 3 and Figure 4).

\subsection{Anesthesia}

Patients presented for elective, same day surgery in an accredited University Hospital Surgery Center. All surgeries are categorized as low risk. Types of surgery include lipoma excision, third molar extraction, tonsillectomy, umbilical hernia repair and corneal transplant.

After informed consent was obtained, baseline vital signs were documented. An intravenous line was started, and the American Society of Anesthesiologists (ASA) standard monitoring devices were placed on the patient. All patients underwent standard IV induction of general anesthesia by anesthesiology attending with $2 \mathrm{ug} / \mathrm{kg}$ of fentanyl, $2 \mathrm{mg} / \mathrm{kg}$ of propofol, 1 - $2 \mathrm{mg}$ of midazolam, and $1 \mathrm{mg} / \mathrm{kg}$ of lidocaine. After loss of consciousness, patients received $2 \mathrm{mg} / \mathrm{kg}$ of succinylcholine in preparation for intubation.

After induction of general anesthesia and before placement of the endotracheal tube or laryngeal mask airway, the anesthesia provider performed face mask ventilation to the patient using an adult-sized \#5 facemask. Each facemask was pre-inflated with 150 $\mathrm{cc}$ of room air, and placed over the patient's oral cavity.

The three methods for holding the facemask over the patient's mouth were then performed in the following sequence: CE, NST, THT.

The anesthesia provider then performed the chin lift maneuver to 45 degrees, placed the facemask over the patients' mouth opening, and activated the ventilator 45 seconds after succinylcholine administration.

A preset tidal volume of $8 \mathrm{cc} / \mathrm{kg}$ was delivered for 8 breaths. Any air leaks were noted and minimized by increasing downward pressure on the facemask. Tidal volume (TV), peak airway pressure (PAP), heart rate (HR), oxygen saturation $\left(\mathrm{SaO}_{2}\right)$ and presence or absence end tidal carbon dioxide (ETCO2) were recorded at each breath by an independent observer. TV and PAP were measured using the Datex Ohmeda Aestiva 53000 monitor. BP, SaO2, ETCO2, and HR, were measured using the Philips MP70 monitor.

The same process of ventilator delivered breaths was repeated using the novel submandibular grip followed by the two-handed grip of the provider's choice (either C-E or V-E). Each of the facemask techniques took an estimated 1.5 minutes, for a total of approximately 5 minutes.

For study subjects with tidal volumes less than $1 \mathrm{cc} / \mathrm{kg}$ using the $\mathrm{CE}$ technique, an oral airway was used and ventilation reinstituted. If the patient could not be ventilated to at least $2 \mathrm{cc} / \mathrm{kg}$ after placement of the oral airway, an endotracheal tube was immediately placed, and the study was terminated.

\subsection{Statistical Analyses}

Comparison of the two groups was performed via a 2-sample $t$ test. Analyses of tidal volumes were performed with ANOVA. Chi-square tests, used to assess statistical signi- 
ficance at the $\alpha=0.05$ level, were performed for qualitative reasons only.

As this was a pilot study of a new technique, no previous data existed for the researchers to conduct a power analysis. The data retrieved from this study will be used to construct a larger and more definitive trial. Small sample sizes were selected so that investigators could quickly obtain meaningful trends and rough data. Power analysis was not performed as our primary aim was to determine if the NST was capable of delivering tidal volumes in high risk patients.

\section{Results}

The majority of patients in both groups were male. The average age in the control group was 33 years of age, compared to an average age of 52 in the experimental group (Table 1). Two patients in the experimental group exhibited qualities of two subgroups: one was Mallampati class 3 and was bearded, while the other was Mallampati class 3 and had OSA. No patients were Mallampati class 4 . No patients enrolled in the study were excluded from analyses.

Table 1. Demographic characteristics of study population. BMI: body mass index; OSA: obstructive sleep apnea.

\begin{tabular}{|c|c|c|c|}
\hline No. of patients & & Control & Experimental group \\
\hline \multirow{2}{*}{ Sex } & Male & 7 & 12 \\
\hline & Female & 4 & 7 \\
\hline \multirow{6}{*}{ Age } & $<20$ & 2 & 1 \\
\hline & $21-30$ & 3 & 1 \\
\hline & $31-40$ & 3 & 2 \\
\hline & $41-50$ & 2 & 4 \\
\hline & $51-60$ & 0 & 5 \\
\hline & $>60$ & 1 & 6 \\
\hline \multirow{5}{*}{ BMI } & $<25.0$ & 3 & 4 \\
\hline & $25.0-29.9$ & 5 & 8 \\
\hline & $30.0-34.9$ & 1 & 1 \\
\hline & $35.0-39.9$ & 1 & 4 \\
\hline & $40-45$ & 1 & 2 \\
\hline \multirow{3}{*}{ Mallampati } & 1 & 6 & 3 \\
\hline & 2 & 5 & 8 \\
\hline & 3 & 0 & 8 \\
\hline \multirow{4}{*}{ Other Risk Factors } & Edentulous & & 8 \\
\hline & OSA & & 2 \\
\hline & Bearded & & 4 \\
\hline & Neck irradiated & & 0 \\
\hline
\end{tabular}


In control patients, changing from the conventional one-handed C-E grip (CE) to the two-handed technique (THT) resulted in a $15.4 \%$ increase in tidal volumes delivered, whereas changing from the novel submandibular technique (NST) to the two-handed technique resulted in an increase of $10.0 \%$ (Table 2). The ratio of tidal volumes delivered by CE versus THT in control patients was 0.875 , while the tidal volume ratio delivered by NST versus THT was 0.894 (Table 3 ).

Edentulous patients experienced an increase of $186.9 \%$ in tidal volumes delivered when changing from the NST to the THT, and an increase of $191.8 \%$ in tidal volumes delivered when changing from the $\mathrm{CE}$ technique to the THT (Table 2). In this group, tidal volume ratios were 0.435 (CE:THT) and 0.440 (NST:THT). Patients who were Mallampati 3 or 4 similarly had tidal volume ratios of 0.723 (CE:THT) and 0.810 (NST:THT) (Table 3).

In bearded patients and patients with OSA, the CE grip delivered higher tidal volumes. In an overall analysis of all patients with risk factors, the $\mathrm{CE}$ technique delivered 2.2\% higher tidal volumes than the NST technique (Table 3 ).

As expected, the two-handed technique provided the largest tidal volumes of all three techniques in all patient groups.

Peak airway pressure (PAP), heart rate (HR), and oxygen saturation ( $\mathrm{SaO} 2)$ were found to be similar in all three techniques amongst control and experimental groups.

Table 2. Percentage increase in Tidal Volume upon switching from Novel Submandibular Technique (NST) to Two Handed Technique (THT); and upon switching from Traditional One Handed Grip (CE) to Two Handed Technique (THT).

\begin{tabular}{ccc}
\hline Patient Category & \% Increase NST to THT & \% Increase CE to THT \\
\hline Control & 10.0 & 15.4 \\
Edentulous & 186.9 & 191.8 \\
Mallampati 3 & 33.9 & 44.5 \\
Bearded & 83.3 & 44.3 \\
OSA & 85.1 & 78.6 \\
All Experimental Subjects & 85.1 & 78.6
\end{tabular}

OSA: Obstructive Sleep Apnea; ${ }^{*}$ Experimental Subjects with 2 or more risk factors risk factors were only counted once.

Table 3. Tidal volume ratios of experimental techniques.

\begin{tabular}{ccccccc}
\hline Tidal volume ratios & CE:NST & $p$ & CE:THT & $p$ & NST:THT & $p$ \\
\hline Control & 1.007 & 0.488 & 0.875 & 0.014 & 0.894 & 0.035 \\
Edentulous & 0.955 & 0.618 & 0.435 & 0.013 & 0.440 & 0.014 \\
Mallampati 3 or 4 & 1.160 & 0.509 & 0.723 & 0.035 & 0.810 & 0.193 \\
Beard & 1.566 & 0.408 & 0.669 & 0.198 & 0.561 & 0.193 \\
OSA & 1.541 & 0.843 & 0.531 & 0.372 & 0.505 & 0.431 \\
\hline
\end{tabular}

CE: one-handed C-E technique; NST: one-handed novel sub-mandibular technique; THT: two-handed technique; OSA: obstructive sleep apnea; alpha $=0.05$. 
Additionally, the above parameters were all within the normal ranges while the study was being performed.

No patients experienced a decrease in $\mathrm{SaO} 2$, had a loss of capnography, nor had a change in HR that was clinically significant.

\section{Discussion/Conclusion}

Adequate mask ventilation is vital in both the administration of anesthesia and in general medical practice. However, previous studies have reported rates of difficult mask ventilation ranging from approximately $1 \%$ to as high as $9 \%$ [12]-[16]. This indicates that the incidence of difficult mask ventilation is high and providers must prepare for the difficult ventilation scenario. In situations without the presence of a second caregiver, patients with risk factors for difficult mask ventilation may be particularly challenging. The familiarity of providers with the NST can prevent hypoxic episodes in a variety of emergent scenarios.

According to the study design, all patients in the Experimental Group had one or more Predictors of Difficult Mask Ventilation (Edentulous, Bearded, Obstructive sleep Apnea, Mallampati 3 or 4) as reported in the study by Kheterptal et al., 2006. Study subjects in the Control Group are not considered difficult to mask ventilate. Therefore, they do not have any of the predictors of difficult mask ventilation listed in the study by Kheterpal et al.

Our results show that the novel one-handed sub-mandibular grip can be used as a complement or alternative technique to the traditional one-handed C-E grip in patients with certain risk factors for difficult mask ventilation. The NST delivered higher tidal volumes to edentulous patients and Mallampati class 3 patients than the C-E technique. However, the opposite was true for patients who had beards or OSA, with the C-E technique delivering higher tidal volumes than the NST. The NST's utility in Mallampati class 4 was not assessed in this study, as none of the subjects had a Mallampati 4 airway.

Several limitations to this study must be acknowledged. As a pilot study, only a small group of patients were included in the experimental group and control group. Thus, statistical significance could not be achieved. However, inability to achieve statistical significance does not indicate that the Novel Submandibular shouldn't be taught to airway providers.

Additionally, the two-handed technique used by the anesthesia provider was based on provider preference, and not mandated to be either two-handed V-E or two-handed C-E. Provider familiarity with their preferred two-handed grip may partially account for the improved tidal volumes seen over both the conventional and the novel technique. Lastly, fatigue may play a role in the results, as the novel technique was used after the C-E technique in all patients.

This study shows that a novel one-handed sub-mandibular technique holds promise as an alternative to the traditional one-handed C-E technique in bag-mask ventilation of edentulous and Mallampati 3. Situations in which a second provider is not available 
to assist with ventilation make this a technique that has important implications. Further large-scale studies to investigate the differences between the two one-handed techniques are therefore warranted.

\section{References}

[1] Soleimanpour, H., Gholipouri, C., Panahi, J.R., et al. (2011) Role of Anesthesiology Curriculum in Improving Bag-Mask Ventilation and Intubation Success Rates of Emergency Medicine Residents: A Prospective Descriptive Study. BMC Emergency Medicine, 11, 8. http://dx.doi.org/10.1186/1471-227X-11-8

[2] Services DoHaH, Center for Medicare and Medicaid Services (2011) Transmittal 74: Condition of Participation: Anesthesia Services 42 CFR 482.52.

[3] Apfelbaum, J.L., Hagberg, C.A., Caplan, R.A., Blitt, C.D., Connis, R.T., Nickinovich, D.G., Hagberg, C.A., Caplan, R.A., Benumof, J.L., Berry, F.A., Blitt, C.D., Bode, R.H., Cheney, F.W., Connis, R.T., Guidry, O.F., Nickinovich, D.G. and Ovassapian, A. (2013) American Society of Anesthesiologists Task Force on Management of the Difficult Airway. Practice Guidelines for Management of the Difficult Airway: An Updated Report by the American Society of Anesthesiologists Task Force on Management of the Difficult Airway. Anesthesiology, 118, 251-270. http://dx.doi.org/10.1097/ALN.0b013e31827773b2

[4] Langeron, O., Masso, E., Huraux, C., Guggiari, M., Bianchi, A., Coriat, P. and Riou, B. (2000) Prediction of Difficult Mask Ventilation. Anesthesiology, 92, 1229-1236. http://dx.doi.org/10.1097/00000542-200005000-00009

[5] Takenaka, I., Aoyama, K. and Kadoya, T. (2001) Mandibular Protrusion Test for Prediction of Difficult Mask Ventilation (Letter). Anesthesiology, 94, 935. http://dx.doi.org/10.1097/00000542-200105000-00041

[6] Yildiz, T.S., Solak, M. and Toker, K. (2005) The Incidence and Risk Factors of Difficult Mask Ventilation. Journal of Anesthesia, 19, 7-11. http://dx.doi.org/10.1007/s00540-004-0275-Z

[7] Chou, H.C. and Wu, T.L. (2001) Large Hypopharyngeal Tongue: A Shared Anatomic Abnormality for Difficult Mask Ventilation, Difficult Intubation, and Obstructive Sleep Apnea? Anesthesiology, 94, 936-937. http://dx.doi.org/10.1097/00000542-200105000-00043

[8] Kheterpal, S., Han, R., Tremper, K.K., et al. (2006) Incidence and Predictors of Difficult and Impossible Mask Ventilation. Anesthesiology, 105, 885-891. http://dx.doi.org/10.1097/00000542-200611000-00007

[9] Walls, R. (2008) Manual of Emergency Airway Management. 3rd Edition, Lippincott Williams \& Wilkins, Philadelphia.

[10] Berg, M.D., Schexnayder, S.M., Chameides, L., et al. (2010) Part 13: Pediatric Basic Life Support: 2010 American Heart Association Guidelines for Cardiopulmonary Resuscitation and Emergency Cardiovascular Care. Circulation, 122, S862-S875. http://dx.doi.org/10.1161/CIRCULATIONAHA.110.971085

[11] McCabe, S.M. and Smeltzer, S.C. (1993) Comparison of Tidal Volumes Obtained by One-Handed and Two-Handed Ventilation Techniques. American Journal of Critical Care, 2, 467-473.

[12] Han, R., Tremper, K.K., Kheterpal, S., et al. (2004) Grading Scale for Mask Ventilation. Anesthesiology, 101, 267. http://dx.doi.org/10.1097/00000542-200407000-00059

[13] Asai, T., Koga, K. and Vaughan, R.S. (1998) Respiratory Complications Associated with Tracheal Intubation and Extubation. British Journal of Anaesthesia, 80, 767-775. 
http://dx.doi.org/10.1093/bja/80.6.767

[14] Rose, D.K. and Cohen, M.M. (1994) The Airway: Problems and Predictions in 18,500 Patients. Canadian Journal of Anesthesia, 41, 372-383. http://dx.doi.org/10.1007/BF03009858

[15] Langeron, O., Masso, E., Huraux, C., Guggiari, M., Bianchi, A., Coriat, P. and Riou, B. (2000) Prediction of Difficult Mask Ventilation. Anesthesiology, 92, 1229-1236. http://dx.doi.org/10.1097/00000542-200005000-00009

[16] Cattano, D., Killoran, P.V., Cai, C., et al. (2014) Difficult Mask Ventilation in General Surgical Population: Observation of Risk Factors and Predictors. F1000Research, 3, 204.

Submit or recommend next manuscript to SCIRP and we will provide best service for you:

Accepting pre-submission inquiries through Email, Facebook, LinkedIn, Twitter, etc. A wide selection of journals (inclusive of 9 subjects, more than 200 journals)

Providing 24-hour high-quality service

User-friendly online submission system

Fair and swift peer-review system

Efficient typesetting and proofreading procedure

Display of the result of downloads and visits, as well as the number of cited articles Maximum dissemination of your research work

Submit your manuscript at: http://papersubmission.scirp.org/

Or contact ojanes@scirp.org 